\title{
DESIGN, FABRICATION, INSTALLATION, TESTING AND INITIAL RESULTS OF IN-VESSEL CONTROL COILS FOR DIII-D
}

\author{
by \\ P.M. ANDERSON, C.B. BAXI, A.G. KELLMAN, \\ and E.E. REIS
}

MARCH 2004 


\section{DISCLAIMER}

This report was prepared as an account of work sponsored by an agency of the United States Government. Neither the United States Government nor any agency thereof, nor any of their employees, makes any warranty, express or implied, or assumes any legal liability or responsibility for the accuracy, completeness, or usefulness of any information, apparatus, product, or process disclosed, or represents that its use would not infringe privately owned rights. Reference herein to any specific commercial product, process, or service by trade name, trademark, manufacturer, or otherwise, does not necessarily constitute or imply its endorsement, recommendation, or favoring by the United States Government or any agency thereof. The views and opinions of authors expressed herein do not necessarily state or reflect those of the United States Government or any agency thereof. 


\title{
DESIGN, FABRICATION, INSTALLATION, TESTING AND INITIAL RESULTS OF IN-VESSEL CONTROL COILS FOR DIII-D
}

\author{
by \\ P.M. ANDERSON, C.B. BAXI, A.G. KELLMAN, \\ and E.E. REIS
}

This is a preprint of a paper presented at the 20th IEEE/NPSS Symposium on Fusion Engineering, San Diego, California, October 14-17, 2003 and to be published in Fusion Science and Technology.

\author{
Work supported by \\ the U.S. Department of Energy \\ under Contract No. DE-AC03-99ER54463
}




\title{
Design, Fabrication, Installation, Testing and Initial Results of In-Vessel Control Coils For DIII-D
}

\author{
P.M. Anderson, * C.B. Baxi, A.G. Kellman, and E.E. Reis \\ General Atomics,P.O. Box 85608, San Diego, California 92186-5608 \\ *Phone: (858) 455-4748; Fax (858) 455-4190; email: anderson@fusion.gat.com
}

\begin{abstract}
Since 1995, DIII-D has performed correction of magnetic field imperfections using a set of six external picture frame coils located on the vessel mid-plane. In 2000 , these coils also demonstrated benefits when used for feedback of the resistive wall mode, an instability that limits the plasma performance at high beta. Modeling has shown that substantial performance improvements could be achieved by installing new coils inside the vessel and expanding the poloidal coverage above and below the mid-plane. Two prototype internal coils were installed in 2001 and were power tested successfully after several bakes to $350^{\circ} \mathrm{C}$. A full set of twelve internal coils and related magnetic sensors are now operational in the DIII-D tokamak. The design requirements for the new coil system was to maximize the magnetic field at the plasma edge, operate with a frequency range of dc to $1000 \mathrm{~Hz}$, and fit behind the existing graphite wall tiles. The coil design adopted and installed is a water-cooled hollow copper conductor insulated with polyamide and housed inside a stainless steel tube that forms a vacuum boundary. The coil is rigidly mounted to the inside of the vacuum vessel. The primary challenge in the design of these coils was in joining of both the copper conductor and the stainless tube without overheating the polyamide insulator. Elastic-plastic analysis was used to demonstrate acceptable thermal stresses during baking conditions. Analysis determined the optimum water cooling channel diameter. The coils were tested in high toroidal field to the limit of the power supply of $4.5 \mathrm{kA}$ DC with inductancelimited current for frequencies between $300 \mathrm{~Hz}$ and $1000 \mathrm{~Hz}$. Recent results are presented.
\end{abstract}

\section{DESIGN GOALS}

The key design requirements for the new coil system are to maximize the magnetic field from the coils at the plasma edge, operate with a frequency range of dc to $1000 \mathrm{~Hz}$, and fit in the space behind the existing graphite wall tiles to avoid any plasma contact. The specified voltage standoff is $1000 \mathrm{Vdc}$ from conductor to vessel ground. This provides a factor of 2.5 margin above the expected peak voltage of $\sim 400 \mathrm{~V}$; the coil power supply is capable of a peak voltage of $300 \mathrm{~V}$ while disruptions can add up to $60 \mathrm{~V}$ across the coil terminals. Disruption induced currents can add $4 \mathrm{kA}$ ( $17 \mathrm{kA}$ for a faulted coil) to the normal $5 \mathrm{kA}$ coil current, so the mechanical attachment of the coil to the vessel must be adequate to prevent damage to in-vessel components in the event of a faulted coil condition. The in-vessel coil environment requires a robust design due to high cyclic electromagnetic forces in vacuum and temperatures to $350^{\circ} \mathrm{C}$ during vessel baking.

\section{DESIGN SOLUTION}

Because the size of the ports on DIII-D would not permit a fully assembled coil to be passed into the vessel, the coil either had to be formed in the vessel from a straight section introduced through a port or assembled together inside the vessel from smaller subassemblies. The space available for the coil conductor beneath the graphite wall tiles is approximately a $29 \mathrm{~mm}$ by $29 \mathrm{~mm} \mathrm{sq}$ cross section. Due to the space limitation imposed by the tiles, there is no room to allow for coil turns to cross each other and the coil is limited to single turn construction.

The single turn construction results in a low inductance, high frequency coil set. Fig. 1 shows the two prototype coils that were installed in DIII-D in 2001. The production coils are similar with refined detail features. The production, in-vessel coil set now consist of two sets of six coils each located on the inside of the outer wall on conical surfaces above and below the vessel mid-plane. The coils are single turn with a conductor length of $5 \mathrm{~m}$ and an area of $1 \mathrm{~m}$ sq. In order to minimize error fields and electromagnetic forces, the radially oriented power and cooling water feeds are coaxial. The coils are shielded from the plasma by the plasma facing graphite tiles that are shown partially installed in Fig. 1.

The in-vessel coil design adopted and installed is shown in Fig. 2. It is made of water-cooled hollow copper conductor (14.4 $\mathrm{mm}$ o.d.) insulated with polyamide and housed inside a 304 stainless steel tube ( $19 \mathrm{~mm}$ o.d.) that forms a vacuum boundary. The polyamide insulating layer is comprised of $0.05 \mathrm{~mm}$ Kapton tape (50\% overlap), many $1.7 \mathrm{~mm}$ thick Duport Vespel SP-1 cylindrical spacers, and an additional layer of Kapton tape. The coil conductor system is engineered to operate up to $7 \mathrm{kA} \mathrm{dc}$ steady-state with cooling water flow of $5.5 \mathrm{~m} / \mathrm{s}$. Shop fabrication uses in-air induction brazing of the oxygen free copper conductor joints at the corners of each coil. The copper and polyamide insulation is encased in a welded 304 stainless steel vacuum barrier that is the only material exposed to vessel vacuum. Each coil is fully formed on a mockup in the shop. This process allows the coil to be passed into the vessel in three pieces; a lower conductor assembly, an upper conductor assembly and a $35 \mathrm{~mm}$ diameter concentric lead assembly. This design required in-vessel joining of copper with three induction brazes and six orbital welds of the stainless vacuum jacket.

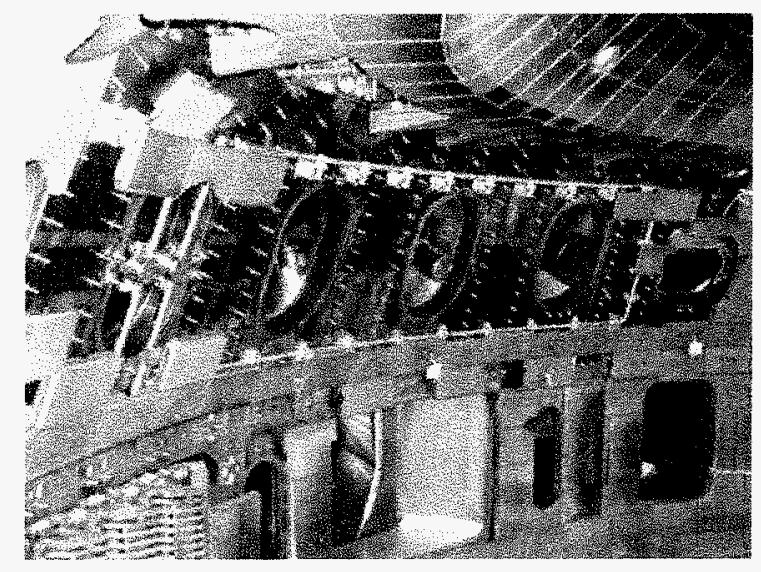

Fig. 1. Installation of 2 prototype I coils, October 2001. 


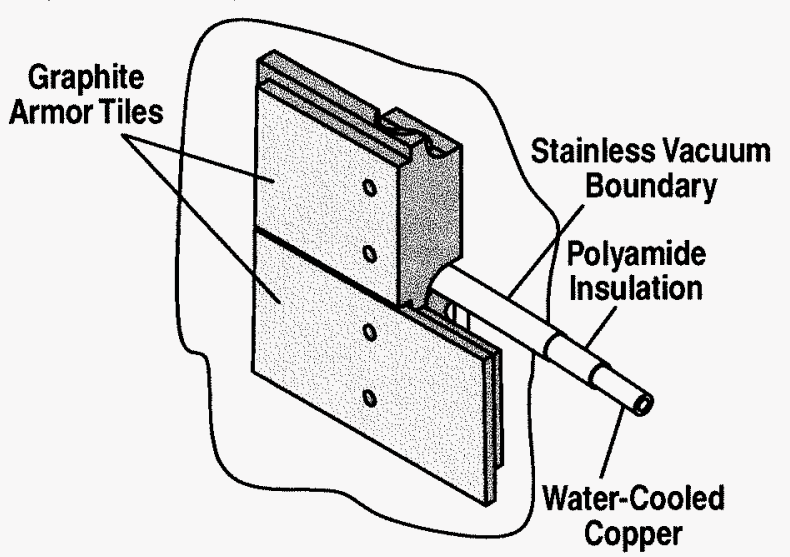

Fig. 2. Construction of internal control coils for a set of 12 single turn, actively water-cooled, copper loops. The coils will be located above and below the midplane and behind the protective armor tiles.

The design provides a double barrier of copper and stainless against cooling water leakage into the tokamak. The polyamide selected, DuPont Vespel SP-1, is hydroscopic and contains about $1 \%$ by mass of water at room conditions. This moisture is evolved as the material is heated to $350^{\circ} \mathrm{C}$ during vessel baking. The insulator is located between the copper and the stainless and could be exposed to atmosphere at both ends of the conductor outside of the vessel. In order to detect water leaks in the copper or leaks through the stainless into the vessel, the insulation space is sealed in two places outside the vessel using machined polyamide and Viton "O" rings. During the initial bake of the vessel, this space is vacuum pumped to remove moisture and gases that evolve. After cool down, dry nitrogen gas is back filled to about 0.3 bar, and sealed. The pressure in this trapped volume is monitored to detect either water leaks through the copper (higher pressure) or stainless sheath leaks to the vacuum (lower pressure). Additional information on interlocks and alarms as given in [2]. During vessel baking, the cooling water in the coils is replaced with dry nitrogen in order to limit oxidization of the copper.

The peak voltage across the polyamide insulator is limited to $1000 \mathrm{~V}$ by a varistor connected between the conductor and the vessel grounded sheath of each coil.

\section{DEVELOPMENT ISSUES}

The primary challenge in the design of these coils was in joining of both the copper conductor and the stainless tube without overheating the polyamide insulator. Early testing indicated that the hollow copper conductor could be brazed in air without overheating polyamide insulation located $50 \mathrm{~mm}$ axially from the braze joint. This process depends on rapid localized heating of the copper. A transient axial thermal gradient of over $815^{\circ} \mathrm{C}$ at the braze to less than $400^{\circ} \mathrm{C}$ at the polyamide is required. This was achieved with localized induction heating of about $10 \mathrm{~kW}$ for about $13 \mathrm{~s}$. Similar polyamide overheating problems were evident when TIG welding the stainless steel tubing which contacted the polyamide. A solution was developed using automated orbital welding of the stainless steel tube to produce controlled and repetitive heat input. Specially designed joints that dissipate the welding heat throughout a large mass acceptably limits the peak temperature at the polyamide. A second issue with the welding process is trapping of pressurized gas within the stainless sheath due to out-gassing of the polyamide during the welding process. This trapped gas caused weld blowout near the closure of the orbital weld. This problem was corrected on the prototype coils with manual weld repair. Gas vents were developed for the production coils to prevent blowout. These $2.5 \mathrm{~mm}$ vent holes are then plugged with a set-screw and seal welded manually. The brazing and welding processes are performed both outside and inside of the vacuum vessel.

\section{THERMAL AND STRESS ANALYSIS}

Thermal analysis of the resistive heating and water cooling of the copper as well as transient temperatures during vessel baking was done to evaluate heat removal and thermal stresses. The copper conductor was limited in diameter to $14.4 \mathrm{~mm}$ by space constraints, the thickness of the sheath tube and the polyamide insulator. The copper and water cross sections for the conductor were optimized to maximize dc steady-state current without exceeding a water outlet temperature of $90^{\circ} \mathrm{C}$ for water flow of $5.5 \mathrm{~m} / \mathrm{s}$ and an inlet temperature of $35^{\circ} \mathrm{C}$. The $5 \mathrm{~m}$ long conductor coil can handle $7 \mathrm{kA}$ dc steady-state, as limited by $53^{\circ} \mathrm{C}$ water temperature increase. Thermal steady-state is reached after $8 \mathrm{~s}$ of constant input power. The increase in water temperature occurs during the one second period the water requires to transit the $5 \mathrm{~m}$ long conductor.

Stress analysis was done for $\mathrm{I} \times \mathrm{B}$ forces and thermal stresses developed during vessel bake-out. With alternating coil current at frequencies as high as $1 \mathrm{kHz}$, there were concerns about high cycle fatigue of the copper and stainless. The coil conductor is clamped rigidly to the Inconel 625 vessel wall at intervals less than $180 \mathrm{~mm}$. Although finite element analysis predicted a first resonance of the single conductor at $980 \mathrm{~Hz}$, no resonances were detected during frequency sweeping to $1000 \mathrm{~Hz}$ in a strong magnetic field. The cyclic bending stress in the copper due to a $5 \mathrm{kA}$ coil current reacting with the $2.2 \mathrm{~T}$ toroidal field is $35 \mathrm{Mpa}$ and compares with a room temperature yield strength of $69 \mathrm{Mpa}$ for annealed copper. This provides an expected fatigue life of greater that $10^{10}$ cycles, sufficient for $10^{6}$ full current, $10 \mathrm{~s}$ pulses at $1 \mathrm{kHz}$. Of greater concern is the low cycle fatigue experienced during baking cycles that occur about 10 times a year. The vessel temperature rise from $20^{\circ} \mathrm{C}$ to $350^{\circ} \mathrm{C}$ requires $5 \mathrm{hrs}$ ( 8 hrs for cool-down) and the temperatures of the Inconel vessel, the coil components of stainless, polyamide and copper are reasonably uniform due to conduction and thermal radiation between materials. Thermal stresses develop during baking due to differences in the rate of thermal expansion between the Inconel 625 wall, stainless 304 sheath and the oxygen free copper conductor. These thermal expansion rates are $1.76 \times 10^{-5}$ for stainless and copper and $1.55 \times 10^{-5}$ for Inconel. The main concern is compressive stresses that develop in the copper conductor as the thermal expansion of the copper is restrained by the stainless sheath, which is rigidly attached to the relatively stiff Inconel vessel. The copper is fully annealed during each bake cycle to $350^{\circ} \mathrm{C}$. With this type of thermal cycling, the thermal stresses shake down to acceptable levels. The highest stresses occur during the first bake since most of the copper starts in the hard, high strength condition. The elastic-plastic stress versus strain cycle during bake-out at a brazed elbow copper joint is shown in Fig. 3. The total strain at the worst case OFHC elbow joint during cool-down from bake-out is $0.14 \%$. This total strain applied to 


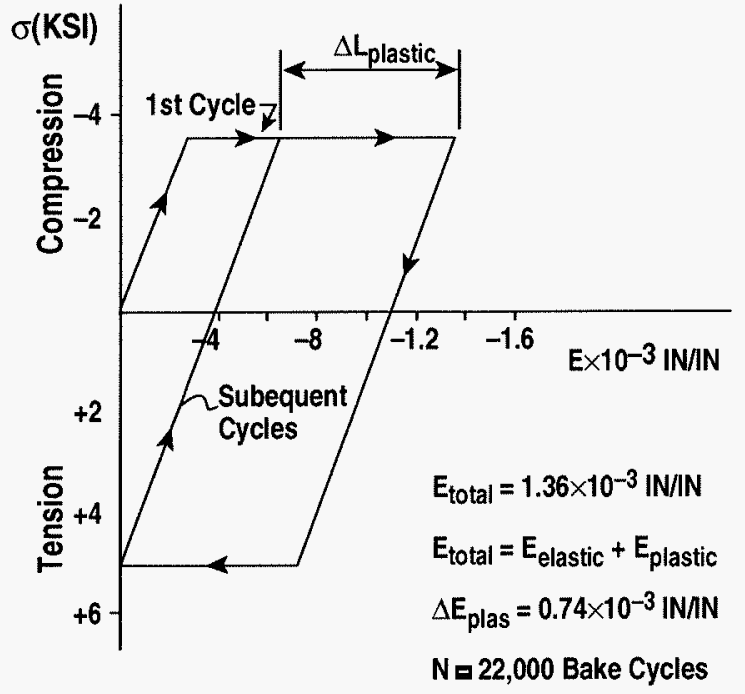

Fig. 3. Plastic strain range at copper elbow during bake-out/ cool-down cycle.

the stress curves for annealed OFHC translates to an alternating plastic strain of $0.074 \%$. The allowable number of cycles at this plastic strain range is 20,000 cycles based on the lower bound fatigue curve of [3] as shown in Fig. 4. We typically perform only $10-15$ bakes per year, so this anticipated lifetime is more than sufficient for our use. The two prototype coils and the 12 production coils all have experienced about twelve bake cycles to $350^{\circ} \mathrm{C}$ without problems.

\section{PROTOTYPE TESTING}

The initial operation of the twelve internal coils in 2003 was to power them with supplies capable of $5000 \mathrm{~A}$. The two prototype coils installed in Summer 2001 were tested to the full capability of those supplies. This testing included the following:

- Coil cooling tests: $4.5 \mathrm{kA}$ dc for $7 \mathrm{~s}$ which generated $22.7 \mathrm{~kW}$ of heat in the coil as compared to the steadystate design rating of $59 \mathrm{~kW}$. No anomalous heating was observed. A slight increase in coil resistance was measured $(\sim 200 \% @ 1 \mathrm{kHz})$ by water flow calorimetry. This increase is expected due to the decreasing skin depth in the copper conductor at $1 \mathrm{kHz}$.

- Power testing: $4.5 \mathrm{kA}$ delivered from dc $-300 \mathrm{~Hz}$ as limited by the power supply with delivered current decreasing to $1.5 \mathrm{kA}$ at $1000 \mathrm{~Hz}$ as limited by the inductance of the system cabling.

- Mechanical Testing: frequency sweeping from 0 to $1000 \mathrm{~Hz}$ with maximum tokamak poloidal and toroidal fields to monitor for coil mechanical resonances. None were detected by strain gages on the stainless coil sheath. Operation at $4.5 \mathrm{kA}, 250 \mathrm{~Hz}$ for 12,500 cycles at maximum and toroidal fields to perform fatigue tests. No failures were observed.

- Hi pot testing: the installed coils were tested to $4.8 \mathrm{kV}$ for early mechanical assemblies before brazing or welding and to $2.4 \mathrm{kV}$ after welding or brazing. The installed coils were tested to $1.2 \mathrm{kV}$ after installation. Prototype developmental component parts were tested in air to failure that occurred between 6 and $9 \mathrm{kV}$.

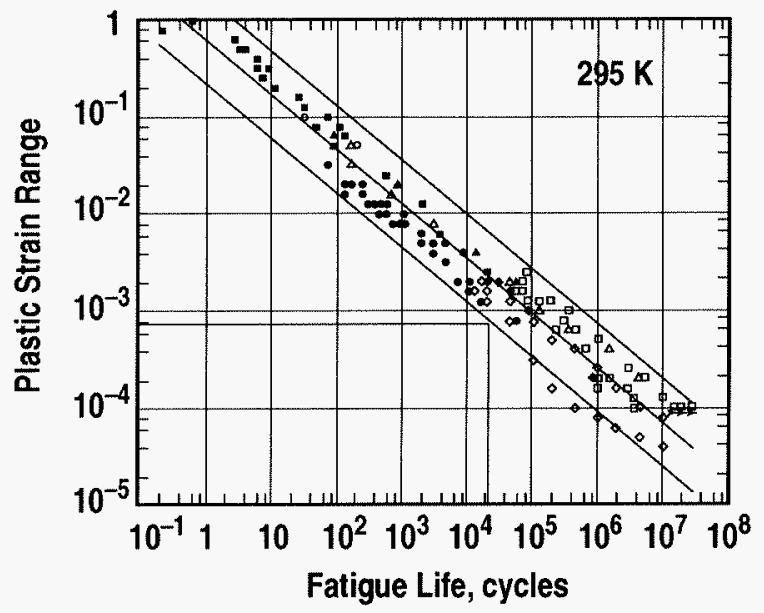

Fig. 4. Strain-controlled axial fatigue curve for $\mathrm{OFHC}$ copper [3].

AC hi pot testing was performed with $\mathrm{a} \pm 400 \mathrm{~V}$, $10 \mathrm{kHz}$ square wave for $-36 \mathrm{hrs}$. with no insulation failure.

Prior to cutting the 2 prototype coils required for removal from the vessel, they were dc hi pot tested in nitrogen to failure which occurred at $4.9 \mathrm{kV}$ and $5.9 \mathrm{kV}$.

After removal, a section of a prototype coil and insulation was saturated with cooling water and hi potted to $1.0 \mathrm{kV}$ without breakdown. This was done to assure safe system operation during a faulted condition of a water leak.

\section{INITIAL PHYSICS RESULTS}

Fusion power density increases with the square of the plasma pressure and thus a goal of the advanced tokamak research program is to maximize the value of normalized plasma pressure or $\beta\left(\beta=<p>2 \mu_{0} / B^{2}\right)$ that can be obtained. However, as the plasma pressure is increased, an instability develops that limits the pressure and can lead to a complete and rapid loss of plasma energy, referred to as a disruption. This instability can be stabilized by the presence of a nearby conducting wall surrounding the plasma and the maximum beta that can be obtained is when the plasma is in close proximity to a perfectly conducting wall. In the presence of a resistive wall, the instability grows more slowly, but starts at a much lower value of normalized pressured, the "no-wall" beta limit. This is referred to as a resistive wall mode and it can be stabilized by rapid rotation of the plasma past the resistive wall or by direct feedback on the magnetic field perturbations caused by the mode. The primary purpose of the new coil set was to permit feedback stabilization of the resistive wall mode instability and to permit plasma beta values approaching the ideal wall limit to be obtained. Initial experiments with the coil have clearly demonstrated the effectiveness of the coil in controlling this instability. In addition, the flexibility of the new coil system has permitted a wide range of additional experiments to be performed that makes the new coils an important tool in our plasma control arsenal.

Initial experiments were conducted to demonstrate the controllability of the new coil set [4]. In these experiments, a magnetic field perturbation was applied from an external coil 
set and the coils were successfully configured and controlled to null out the external field. The coils were connected into six pairs of coils, each with its own power supply and feedback loop set up to cancel the field perturbation measured by internal magnetic probes.

In the next series of experiments (Fig. 5), results indicate that the I-coil provides effective correction of the intrinsic magnetic field irregularities that can slow plasma rotation. This correction has permitted sustained high plasma rotation, which in turn stabilizes the high beta resistive wall mode and permits operation at pressures well above the no-wall limit. For comparison, a discharge with the field correction turned off early in the discharge demonstrates how rapidly plasma rotation is lost and the normalized plasma pressure decreases sharply. As expected by theory, the control was achieved with approximately one fourth of the current that was required by the earlier external coil set because of the closer proximity of the new coils to the plasma than the external coils and to the improved matching of the magnetic structure of new I-coil control field to the plasma instability field structure.

In separate experiments, the I-coil magnetic field was controlled by direct feedback to oppose the bulging of the plasma that occurs as the instability grows. In this experiment, the I-coil permitted the plasma pressure to be maintained at a steady value above the predicted no-wall pressure limit.

The ability to separately power and control the 12 coils permits a wide range of field structures to be produced by the new coil set. In one of the more novel uses, the coils were configured to produced a stochastic field structure at the plasma edge [5]. This type of field structure changes the typical sharp plasma boundary to a broader and less well defined pattern in order to affect the heat load distribution to the first wall. Preliminary results from these experiments indicated that both the peak heat load was reduced and the bursting behavior associated with edge localized modes (ELMs) typically observed in high performance tokamak plasmas was reduced. These results hold great promise for a solution to the serious engineering problems associated with these ELM heat loads.

\section{I-COIL NITROGEN LEAK INTO VACUUM VESSEL}

After approximately six months of operation, a leak developed through the stainless steel barrier between the

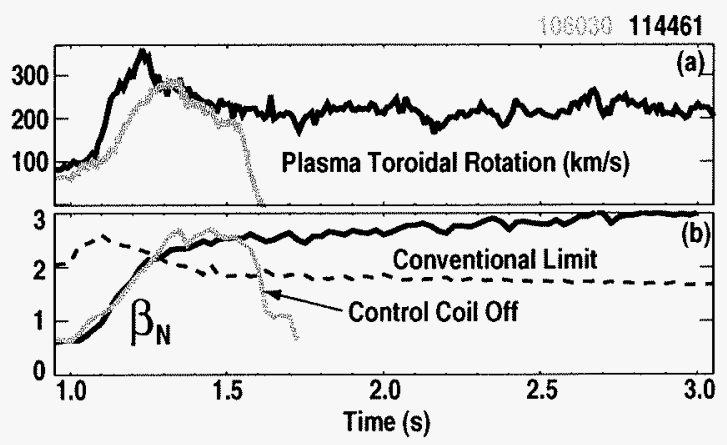

Fig. 5. (a) Application of the I-coil (black curve) provides effective correction of the magnetic field irregularities which permits sustained high plasma rotation. (b) The high rotation permits plasma pressure above the conventional limit to be maintained. When correction current is turned off (grey curves), rotation drops, instability grows and pressure drops. nitrogen pressurized polyamide space and the vacuum vessel on one of the I-coils. This occurred during an experiment with $4.5 \mathrm{kA}$ at $100 \mathrm{~Hz}$, semi-square waveform in all I-coils. This was the first experiment that produced parallel current flow in adjacent verticle legs of a pair of coils that share a common vessel port. In all previous experiments currents in adjacent vertical legs were always phase shifted by at least $60^{\circ}$. This experiment also produced small, but measurable vessel vertical vibrations at $100 \mathrm{~Hz}$. The maximum amplitude required several cycles to develop and had not been evident during frequency sweeping testing or operation in feedback mode which is continuously adjusting the current and frequency applied to each of the 12 coils. Following the leak, the coil was disconnected from the nitrogen system, the insulation area was evacuated with continuous vacuum pumping and plasma experiments resumed without current in any I coils.

Subsequent inspection indicated no melting but similar cracks were visible in both coils that have current leads in the $180^{\circ}$ upper port. Only one lead was leaking through a semicircular crack in a machined transition that joins the concentric lead to the single conductor coil. There are two transitions per coil and the other 22 transitions had no visible cracks. Acceptable bending stresses are expected in these areas during baking and powered operation of the I-coils. It is probable that the crack was the result of operating the coils at a frequency near a vertical resonance of the concentric lead. Three different styles of vessel ports were used for coil leads. The two concentric leads that developed cracks were the longest leads and would therefore have a lower primary natural frequency than the other leads which were not damaged. Investigation and analysis is continuing. Reinforcement and sealing of the damaged coils is planned for October 2003. Restrictions and/or interlocks may be imposed for further operation.

\section{ACKNOWLEDGMENT}

Work supported by U.S. Department of Energy under Contract DE-AC03-99ER54463.

\section{REFERENCES}

[1] A.G. Kellman, "Recent progress from the DIII-D program," to be published in Fusion Engineering and Design.

[2] G.L. Campbell, et al., "Data acquisition And protection for new DIII-D in-vessel coils," these proceedings.

[3] "Properties of copper and copper alloys at cryogenic temperatures," NIST Monograph 177, National Institute of Standards and Technology, (1992) 4-22.

[4] G.L. Jackson, et al., "Initial results from the new internal magnetic field coils for resistive wall mode stabilization in the DIIIU-D tokamak," Proc. of the 30th European Physical Society on Controlled Fusion and Plasma Physics, St. Petersburg, Russia, (2003), to be published in the proceedings.

[5] T.E. Evans, et al., "Suppression of large edge localized modes in high confinement (H-mode) DIII-D plasmas with a stochastic magnetic boundary layer," to be submitted to Phys. Rev. Lett. 